\title{
Ureterovesical Junction
}

National Cancer Institute

\section{Source}

National Cancer Institute. Ureterovesical Junction. NCI Thesaurus. Code C106202.

The area where the ureter joins the urinary bladder. 